\title{
Measuring hope during the COVID-19 outbreak in the Philippines: development and validation of the state locus-of-Hope scale short form in Filipino
}

\author{
Allan B. I. Bernardo ${ }^{1}$ (1) $\cdot$ Norman B. Mendoza $^{2}$ (1) \\ Published online: 25 June 2020 \\ (C) Springer Science+Business Media, LLC, part of Springer Nature 2020
}

\begin{abstract}
Various adaptations of the Dispositional Hope Scale have been validated and used for specific research and applied purposes. The Locus-of-Hope Scale was developed as a cultural adaptation that measures internal and external aspects of agency related to goalpursuit that are typical in collectivist cultures. The scale has been used to account for variations in well-being-related factors in collectivist societies but still assumes that hope-related thoughts are dispositional. A State Locus-of-Hope Scale was developed to assess hope-related thinking concerning ongoing events and experience during the COVID-19 outbreak in the Philippines in March 2020. The 16-item scale in Filipino was adapted from a short version of Locus-of-Hope Scale. Using data from 3128 respondents, confirmatory factor analysis indicated a good fit between the four-factor model (compared to one-factor and twofactor models), supporting the scale's structural validity. There was also good evidence for the subscales' convergent and discriminant validity. Preliminary evidence for construct criterion validity was demonstrated by examining associations with well-being and anxiety. The results indicate the viability of the State Locus-of-Hope scale for assessing temporal hope-related thoughts that can inform efforts to understand how individuals engage in goal-related processes and maintain well-being in specific personal and social situations.
\end{abstract}

Keywords Hope theory $\cdot$ Locus-of-hope $\cdot$ State hope $\cdot$ COVID-19 $\cdot$ Anxiety $\cdot$ Philippines

\section{Introduction}

Snyder's Dispositional Hope Scale (Snyder et al. 1991) is the most extensively used psychological tool to measure hope defined as positive thoughts related to one's capacity and strategies to attain important goals. This self-report measure has been translated into different languages for use in different cultures (e.g., Gana et al. 2013; Sun et al. 2012). As the scale assumes that hope is a trait-like factor measuring goal-related thoughts, a State Hope Scale (Snyder et al. 1996) was developed to measure ongoing hope or goal-related thoughts of individuals. The Locus-of-Hope Scale (Bernardo 2010) was a recent extension and adaptation of the Dispositional Hope

Allan B. I. Bernardo

allan.bernardo@dlsu.edu.ph

1 Psychology Department, De La Salle University, 2401 Taft Avenue, 1004 Manila, Philippines

2 Department of Curriculum and Instruction, The Education University of Hong Kong, Hong Kong, SAR, China
Scale that differentiates internal and external locus-of-hope dimensions; these dimensions distinguish between personal (disjoint) agency and shared (conjoint) agency in the goalrelated thoughts (Markus and Kitayama 2003). The internal and external locus-of-hope dimensions are proposed to more completely capture the range of goal-related thoughts in collectivist or interdependent cultures that emphasize shared agency in goal pursuit (Bernardo 2010).

In March 2020, the Philippines, like many other countries in the world, experienced an outbreak of the novel corona virus or COVID-19. On March 12, the government announced that Metro Manila would be placed under community quarantine effective March 15; but on March 16, an enhanced community quarantine was announced to include the other provinces in the island of Luzon beyond Metro Manila. Thus, starting March 13, many people experienced massive disruptions in their way of life, not to mention the prospect of seeing themselves and their loved ones getting gravely ill. In this context, the assessment of goal-related thoughts concerning ongoing events may be useful and informative, especially, if the tool can assess the range of hopeful thoughts that are important in the Philippines' interdependent culture. 
For this purpose, we developed a State Locus-of-Hope Scale in Filipino, the language widely spoken in Metro Manila. The scale was administered in an online mental health self-check platform that was created for those who want to understand their psychological well-being during the outbreak. The survey also included other measures of physical and mental health. This study reports the initial results of the structural validation and criterion validation of the State Locus-of-Hope Scale in Filipino based on the data provided by participants of the online self-check questionnaire.

\section{Hope Theory: Assumptions, Adaptations, and Measurements}

Snyder's hope theory (Snyder et al. 1991; Snyder 1994) has provided the most widely used theoretical definition of hope in psychology research. The theory defines hope as a disposition to engage in positive goal-directed thinking, and it assumed to comprise two related components, often referred to as agency and pathways. Agency refers to persons' perceptions regarding their capacity for initiating and persisting on actions to pursue important goals. Pathways refers to individuals' perceptions regarding their ability to generate the plans and strategies for pursuing these goals. The Dispositional Hope Scale (Snyder et al. 1991) is a self-report measure of these two components of hope that has been used in various studies that aim to understand the correlates and positive consequences of hopeful thinking (see Cheavens et al. 2005, for review). The scale has been widely translated and validated in many different languages for use in different countries (e.g., Galiana et al. 2015; Gana et al. 2013; Moreira et al. 2018; Sun et al. 2012).

Although hope has been defined as a trait-like factor (hence, dispositional), Snyder et al. (1996) proposed that there is also theoretical and practical usefulness for conceptualizing a temporal state of hope that refers to thoughts related to ongoing events and goals, and to perceived current agency and pathways related to these goals. In this regard, the State Hope Scale was developed (Snyder et al. 1996). This scale has been used to study changes in athletic and academic performance of student athletes (Curry et al. 1997), to measure changes in hope due to positive interventions (Vilaythong et al. 2003) and rehabilitation programs (Fukui et al. 2011), among others.

There have been various adaptations of hope theory and its measure. For example, the theory was adapted to specifically measure hope among patients with rare health conditions (Vernberg et al. 2005) and among employees in the work setting, for which a Work Hope Scale was developed (Juntunen and Wettersten 2006). Hope theory was also adapted to measure hope in society, and a Social Hope Scale was similarly proposed (Jin and Kim 2019). A culture-based adaptation of hope involved the extension of the concept as having internal and external locus-of-hope dimensions
(Bernardo 2010). A cultural reading of hope theory distinguished between different cultural models of agency (Markus and Kitayama 2003) and indicated that goaldirected thinking was assumed to involve only personal agency and capacity, representing a disjoint model of agency that was common in western societies with strong individualist orientations. In contrast, in collectivist societies, goal-pursuit may involve shared or conjoint models of agency, where external actors (family and peers) or forces (spiritual beings) are seen as playing important roles in goal pursuit (Bernardo 2010). In this regard, the Dispositional Hope Scale was adapted to distinguish the internal locus-of-hope (i.e., Snyder's scale) and three external locus-of-hope dimensions: external-family, external-peer, and external-spiritual.

The Locus-of-Hope Scale (Bernardo 2010) has been validated with children (Bernardo 2015) and in different Asian (Bernardo et al. 2016; Du et al. 2015) and North American (Munoz et al. 2019; Wagshul 2019) samples. Consistent with the cultural assumptions, studies have shown how the internal locus-of-hope relate to individualism and independent selfconstruals, while external loci-of-hope relate to collectivism and interdependent self-construals (Bernardo 2010; Du and King 2013).

\section{Positive Correlates of Internal and External Locus-of-Hope}

The availability of reliable measures of dispositional hope has allowed for extensive research to documents the positive correlates and consequences of dispositional hope (or internal locus-of-hope). As its origins were in the field of positive psychology, early research showed positive associations between dispositional hope and well-being (Cheavens et al. 2005; Snyder 1994) even among individuals in very challenging circumstances like survivors in post-disaster contexts (Zhou et al. 2019), victims of bullying (You et al. 2008), and at-risk low-income youth (Adelabu 2008; Raats et al. 2019). Research also documented positive effects of disposition hope on reducing symptoms of anxiety and depression (Arnau et al. 2007; Visser et al. 2013), nonsuicidal self-injury (Jiang et al. 2018; Jiang et al. 2020), and other forms of psychological distress (Berendes et al. 2010). Research also shows numerous positive correlates of dispositional hope or internal locus-of-hope in education, such as with academic functioning (Bryce et al. 2020), success-oriented behavior (Dixson 2019), and achievement in academics (Tomás et al. 2020) and sports (Curry et al. 1997).

As external locus-of-hope is a relatively newer construct, empirical evidence for its positive correlates is not as extensive. Much of the evidence points to positive associations with different facets of well-being even after controlling for the effects of internal locus-of-hope. For example, external locus-of-hope dimensions are positively associated with life- 
satisfaction (Bernardo and Estrellado 2017b; Bernardo et al. 2018a; Munoz et al. 2019), relational self-esteem and communal mastery (Bernardo et al. 2018b; Du et al. 2015), coping (Bernardo et al. 2017), among other positive outcomes. Some positive correlates in the educational domain have also been observed, such as with spontaneous collaborative learning (Bernardo et al. 2016) and academic achievement (Lucas and Ouano 2018). There are some studies that also found that external locus-of-hope buffers the effect of stress on well-being (Bernardo and Resurreccion 2018; Datu and Mateo 2017), and is associated with help-seeking among women victims of intimate partner violence (Bernardo and Estrellado 2017a). A recent study found that external locus-of-hope relates to reduced acquired capability for suicide in an American sample (Wagshul 2019).

\section{State Locus-of-Hope Scale Development and Validation}

Even as much has been learned about the positive correlates of disposition locus-of-hope dimensions, there is value in measuring temporal hope as suggested by Snyder et al., (1996). But the state version of the Locus-of-Hope Scale has not yet been developed, which constrains attempts to assess temporal hope in cases when the individual's agency and pathways may be challenged by unusual circumstances. For example, in situations like the COVID-19 outbreak, there could be some use in knowing people's goal-related thoughts and how these thoughts change as a function of changing social and physical factors. With this in mind, we developed a state-version of the Locus-of-Hope Scale following the procedures for developing the State Hope Scale. As we wanted to use this state-version of the scale among Filipinos, we first referred to the validated Filipino version of the Locus-of-Hope Scale (Bernardo and Estrellado 2014), a short 20-item version with just four items for each of the four subscales and four filler items. The first modification was in the instructions, where participants were asked to take some time to think about what was going on in the lives at present. Second, the items in the scale were reworded so that they referred to the respondents' current goals, and perceptions of agency and pathways at present. Finally, all filler items were removed. The revised items were reviewed by three psychologists, who suggested revisions in the use of words to improve readability (see Appendix for sample items).

To validate the State Locus-of-Hope Scale in Filipino, the scale was administered to a sample of Filipino speaking respondents from Metro Manila in an online survey. The validation focused on establishing the structural validity of the four-factor structure using confirmatory analysis. The convergent and discriminant validity of the state locus-of-hope subscales were then evaluated. Then preliminary evidence for the criterion validity of the scale was obtained by examining the relationship between each of the four state locus-of-hope subscales and measures of general well-being and of anxiety.

\section{Method}

\section{Participants}

Participants were 3182 Filipino citizens from Metro Manila, who gave their informed consent to participate in an online survey. The sample consists of 757 men (23.79\%) and 2425 women $(76.21 \%)$ with ages ranging from 18 to 68 years $(M=$ 26.51; $S D=6.80)$. Majority of the sample were single $(n=$ $2719,85.45 \%$ ). More than $55 \%$ of the total sample were employed at the time of the survey $(n=1777)$.

\section{Procedures}

Participants were recruited through posts shared in social media, so the sample is convenience sample that was not randomly selected. The scales were included in an online self-evaluation questionnaire created to provide a platform for those who intend to understand their psychological and emotional well-being during the COVID-19 pandemic and the implemented enhanced community quarantine declared by the Philippine government on 16 March 2020. The data collection started on 23 March and ended on 30 March. The platform included an Informed Consent section containing the details of their participation including the nature and objectives of the study, their rights as participants, and data confidentiality. Those who did not consent or discontinued their participation were excluded in the sample. No personal identifiers were collected.

\section{Measures}

The State Locus-of-Hope Scale-Short Form in Filipino is the 16-item scale adapted by the researchers from the Locus-ofHope Short Form in Filipino (Bernardo and Estrellado 2014) using the adaptation procedures described Snyder et al. (1996), as discussed in the Introduction section. The 16 items in the scale comprised four items for each of the four locus-ofhope dimensions: internal, external-family, external-peer, and external spiritual; the items were arranged in one fixed random order. Sample items for each of the scales with the English translation are shown in the Appendix. The participants were asked to indicate their agreement with each item using a scale from 1 (strongly disagree) to 4 (strongly agree).

To investigate the criterion validity of the scale, two measures were used, one to assess well-being and another to assess anxiety. For well-being the Mental Health Continuum Short Form (MHC-SF; Keyes et al. 2002) was used. This is a 14item measure of general well-being, with items pertaining to 
emotional, psychological, and social well-being rated from 1 (never) to 6 (everyday). The MHC-SF was in English and had to be translated into Filipino. Three psychology researchers, who were proficient in both English and Filipino and were knowledgeable about principles of psychological assessment and test construction, undertook the translation using forward and backward translation procedures for translation. Each member of the team was independently assigned to do either forward or backward translation of specific scale items and instructions. The final translated scales were then reviewed by all three translators following the methods provided by Epstein et al. (2015). The GAD-7 in Filipino was used to measure general anxiety (Spitzer et al. 2006). It consists of seven items describing anxiety symptoms to which participants indicated whether they experienced each one using a scale rated from 0 (not at all) to 3 (not at all).

\section{Results}

There were no missing data in the dataset. All the data analyses reported below were conducted using Stata 14 MP (StataCorp 2015). The main descriptive statistics (including Cronbach alphas computed using the current sample data) for the state locus-of-hope subscales and total scale, the well-being and anxiety measures are summarized in Table 1.

\section{Structural Validity of the State Locus-of-Hope Scale}

We first assessed the structural validity of the four-factor state locus-of-hope scale using confirmatory factor analysis (CFA). We tested three models: (a) a one-factor model where all the 16 items of the scale indicated one state-hope factor, (b) a two-factor model where 4 items indicated one internal state locus-of-hope factor and the other 12 items indicated an external state locus-of-hope factor, and (c) the hypothesized four-factor model, with 4 items indicated each of the four state locus-of-hope factors. For each CFA, all items were treated as continuous data, and maximum-likelihood was used as the estimation method. Chi-square $\left(\chi^{2}\right)$, comparative fit index (CFI), Tucker-Lewis index (TLI), root-mean-square error of approximation (RMSEA), and standardized root mean square residual (SRMR) were utilized to assess the goodness of fit of the models. CFI and TLI values $>.90$ were regarded as adequate fit, while values $>.95$ were considered as good fit. RMSEA values $<.08$ and $<.06$ were interpreted as indicating adequate and excellent fit, respectively. An SRMR value $<.08$ is considered as good fit and .00 is a perfect fit $(\mathrm{Hu}$ and Bentler 1999).

All three CFA models ran normally after 4 to 10 iterations. Due to a large sample size, all chi-square values of the three CFA models were significant (Tanaka 1987). However, considering all fit indexes, the one-factor $\left[\chi^{2}(104)=14,745.09\right.$, $p<.001, \mathrm{CFI}=.54, \mathrm{TLI}=.47, \mathrm{RMSEA}=.21,90 \% \mathrm{CI}[.00$, $.00], \mathrm{SRMR}=.18]$ and two-factor $\left[\chi^{2}(103)=12,612.68\right.$, $p<.001, \mathrm{CFI}=.61, \mathrm{TLI}=.54, \mathrm{RMSEA}=.20,90 \%$ CI $[.00$, $.00], \mathrm{SRMR}=.18]$ models showed poor fit with the data. Even after restricting error covariances of those with high modification indices, the one-factor and two-factor models still exhibited poor model fit. In contrast, the four-factor model (see Fig. 1) showed good fit with the data $\left[\chi^{2}(98)=1352.34\right.$, $p<.001, \mathrm{CFI}=.96, \mathrm{TLI}=.95, \mathrm{RMSEA}=.06,90 \%$ CI $[.06$, $.07], \mathrm{SRMR}=.04]$. These results provide support for the structural validity of the State Locus-of-Hope Scale.

\section{Convergent and Discriminant Validity of the State Locus-of-Hope Subscales}

With support for the four-factor structure of the state locus-of-hope scale, we then evaluated the convergent and discriminant validity of the subscales. The pertinent results are summarized in Table 2. We first considered two measures of reliability, the composite reliability (CR) and maximal reliability $(\operatorname{MaxR}(\mathrm{H}))$, both of which should be greater than .70 .
Table 1 Descriptive statistics and bivariate correlations among the study variables

\begin{tabular}{lccccccc}
\hline Variables & 1 & 2 & 3 & 4 & 5 & 6 & 7 \\
\hline 1. State LOH total & $(.89)$ & $.74^{* * *}$ & $.78^{* * *}$ & $.66^{* * *}$ & $.75^{* * *}$ & $.66^{* * *}$ & $-.27^{* * * *}$ \\
2. State Internal LOH & & $(.78)$ & $.48^{* * *}$ & $.41^{* * *}$ & $.41^{* * *}$ & $.66^{* * *}$ & $-.32^{* * *}$ \\
3. State External-Family LOH & & & $(.88)$ & $.41^{* * *}$ & $.41^{* * *}$ & $.48^{* * *}$ & $-.21^{* * * *}$ \\
4. State External-Peer LOH & & & & $(.84)$ & $.220^{* * *}$ & $.37^{* * *}$ & $-.11^{* * *}$ \\
5. State External-Spiritual LOH & & & & & $(.95)$ & $.46^{* * *}$ & $-.19^{\text {**** }}$ \\
6. Well-being & & & & & & $(.91)$ & $-.41^{\text {**** }}$ \\
7. Anxiety & & & & & & & $(.86)$ \\
Mean & 47.00 & 11.61 & 11.91 & 10.93 & 12.54 & 51.51 & 9.25 \\
SD & 8.01 & 2.20 & 2.75 & 2.52 & 3.43 & 13.37 & 6.48 \\
\hline
\end{tabular}

Note $:$ LOH $=$ locus-of $=-$ hope; coefficients in parentheses are the internal consistency coefficients of the scales $* * * p<.001$ 


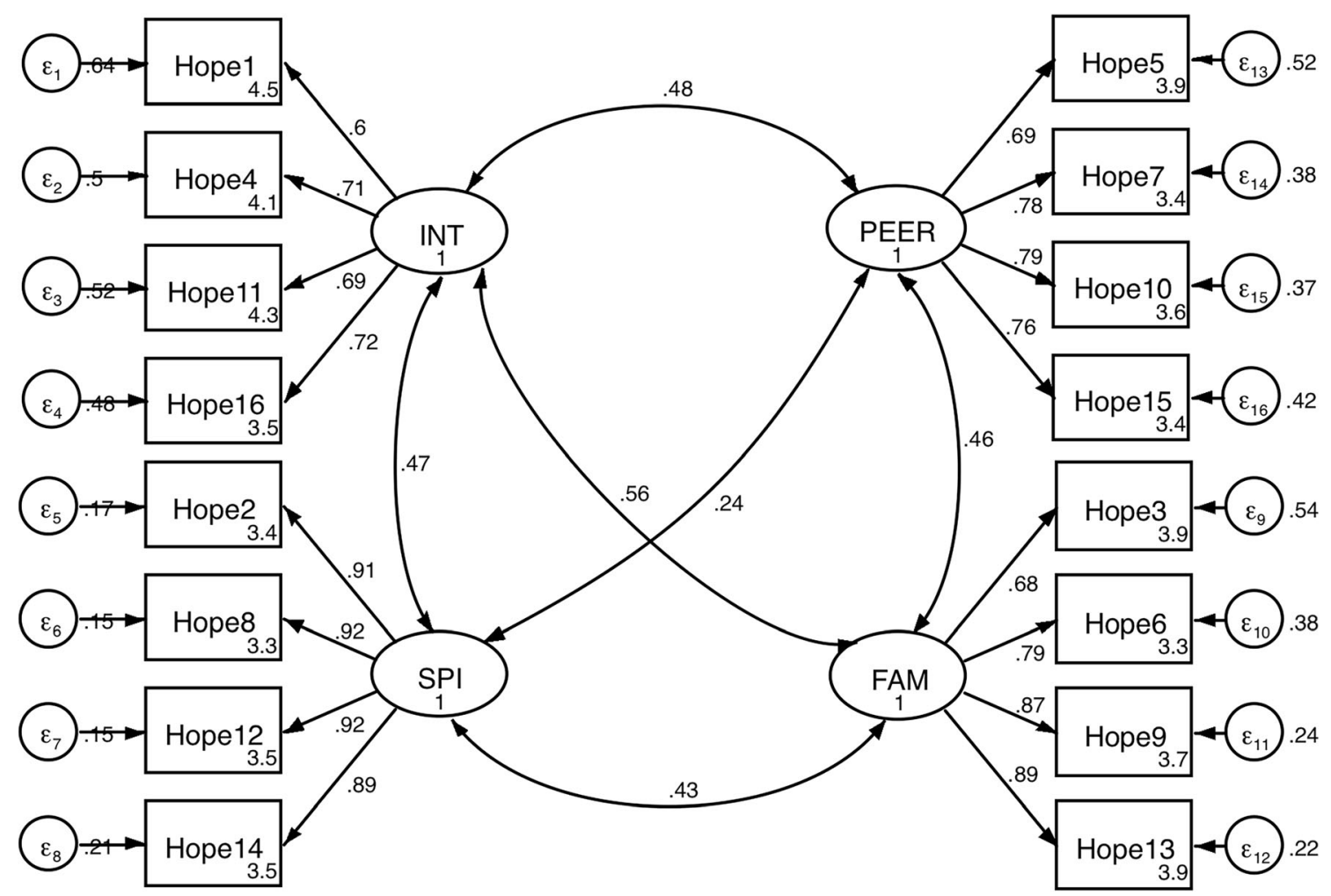

Fig. 1. Visual representation of four-factor model of the State Locus-of-Hope Scale

As shown in Table 3, all the subscales demonstrate good reliability. To evaluate convergent validity, the average variance extracted (AVE) should be greater than .50 and the CR should be greater than the corresponding AVE (Hair et al.2010). As shown in the table, all subscales meet the second criterion, but the state internal locus-of-hope subscale did not meet the AVE criterion. We note that the AVE is considered to be a rather strict and conservative measure of convergent validity by some scholars (e.g., Malhotra and Dash 2011), who suggest that the CR-related criterion should suffice to indicate convergent validity. For discriminant validity, the maximum shared variance (MSV) should be less than the corresponding AVE, and the square root of AVE should be higher than the related correlations (Hair et al. 2010). As Table 2 shows, all four state locus-of-hope subscales demonstrate good discriminant validity.

\section{Criterion Validity of the State Locus-of-Hope Scale}

In order to assess criterion validity, we conducted two sets of hierarchical regression analysis wherein well-being and anxiety were regressed to the four locus-of-hope subscales. Before these analyses, we examined the correlations among the variables (see Table 1) to ensure that there was no multicollinearity; although the pertinent variables were all correlated, the range of the regression coefficients indicated small to moderate sized relationships only. In both regression analyses, age, sex, and marital status were included as control

Table 2 Convergent and discriminant validity statistics of the State Locus-of-hope subscales

\begin{tabular}{|c|c|c|c|c|c|c|c|c|}
\hline \multirow[t]{2}{*}{ State locus-of-hope subscales } & \multirow[t]{2}{*}{$\mathrm{CR}$} & \multirow[t]{2}{*}{ AVE } & \multirow[t]{2}{*}{ MSV } & \multirow{2}{*}{$\begin{array}{l}\text { MaxR } \\
(\mathrm{H})\end{array}$} & \multicolumn{4}{|c|}{ Correlations } \\
\hline & & & & & 1 & 2 & 3 & 4 \\
\hline 1. State internal & .78 & .47 & .23 & .78 & .68 & & & \\
\hline 2. State external-family & .88 & .66 & .23 & .90 & .48 & .81 & & \\
\hline 3. State external-peer & .84 & .58 & .17 & .85 & .41 & .41 & .76 & \\
\hline 4. State external-spiritual & .95 & .83 & .17 & .95 & .41 & .41 & .22 & .91 \\
\hline
\end{tabular}

$\mathrm{CR}=$ composite reliability; $\mathrm{AVE}=$ average variance extracted; $\mathrm{MSV}=$ maximum shared variance; $\mathrm{MaxR}(\mathrm{H})=$ maximal reliability; values in bold italics $=$ square root of AVE 
variables in the first model. We entered age as a continuous variable, while sex and marital status were entered as categorical variables with female and single-most frequent observations - as the reference groups, respectively. For the second model, state internal locus-of-hope was added in the second model, and the remaining three state external locus-ofhope subscales were added to the final model. The hierarchical approach allowed us to examine whether the state external locus-of-hope dimensions explain additional portions of the variance compared to state internal locus-of-hope. The results of the two analyses are summarized in Tables 3 and 4.

As shown in Table 3, older participants, male participants, and married participants seemed to report higher general wellbeing. More pertinent to the criterion validation, state internal locus-of-hope explained a significant portion of the variance in well-being (see Model 2), and the three state external locusof-hope dimensions additionally explained a significant portion of the variance, as well (Model 3). There was a generally similar pattern of results related to anxiety, with some differences. As shown in Table 4, younger participants and female participants reported more anxiety symptoms. Unsurprisingly, state internal locus-of-hope was negatively associated with anxiety. The addition of the state external locus-of-hope subscales improved the regression model, but the change in $R^{2}$ was very small. Still, all three subscales were significantly associated with anxiety. Interestingly, state external-peer locus-of-hope was positively associated with anxiety, while the other two were negatively associated with anxiety, as was expected.

\section{Discussion}

The goal of this study was to validate a state version of the Locus-of-Hope Scale (Bernardo 2010) in the Filipino language that could be used to assess hope-related thinking concerning the ongoing situation of Filipinos during the COVID-19 outbreak. The apparent levels of distress observed among Filipinos during outbreak motivated the development of the state version of the scale that has always measured locus-of-hope as a dispositional construct. The results provide support for the structural validity of the four-factor scale, for the convergent and discriminant validity of the subscales, and initial evidence for its criterion validity, as the scales were generally associated with well-being and anxiety in ways that were expected.

There were some minor concerns observed in the results. First, the AVE for the state internal locus-of-hope scale did not meet the criterion, but there were other indicators of convergent validity of that subscale. Second, although there was a good pattern of relationships between the state locus-of-hope scales and wellbeing, the pattern was not as consistent with anxiety. State external locus-of-hope scales did not seem to improve the regression model for anxiety, compared to the model with state internal locus-of-hope model only; but the model still showed statistically significant relationships between all four state locus-of-hope dimensions and anxiety. Most interestingly, state external-peer locus-of-hope was positively associated with anxiety. Previous research involving (dispositional) external-peer locus-of-hope sometimes pointed to associations with some negative outcomes. For example, in several cultural samples, external-peer locus-of-hope was negatively associated with self-esteem (Du et al. 2015; Bernardo et al. 2018a), and was positively associated with maladaptive forms of coping (Bernardo et al. 2018b). It is possible that hope that depends on the agency of friends might indicate some lack of self-belief, which could explain the positive association with anxiety.
Table 3 Regression results for locus-of-hope subscales predicting well-being

\begin{tabular}{|c|c|c|c|c|c|c|}
\hline & \multicolumn{2}{|l|}{ Model 1} & \multicolumn{2}{|l|}{ Model 2} & \multicolumn{2}{|l|}{ Model 3} \\
\hline & $\beta$ & SE & $\beta$ & SE & $\beta$ & $\mathrm{SE}$ \\
\hline Age & $.29^{* * * *}$ & 0.04 & $.17^{* * * *}$ & 0.03 & $.16^{* * *}$ & 0.03 \\
\hline Sex & $-.06^{* * * *}$ & 0.53 & -.02 & 0.41 & $-.05^{* * *}$ & 0.39 \\
\hline Marital status & $.04^{*}$ & 0.75 & .02 & 0.58 & $.03^{*}$ & 0.57 \\
\hline State Internal LOH & & & $.62^{* * * *}$ & 0.08 & $.45^{* * * *}$ & 0.09 \\
\hline State External-family LOH & & & & & $.14^{* * * *}$ & 0.07 \\
\hline State External-peer LOH & & & & & $.08^{* * * *}$ & 0.07 \\
\hline State External-spiritual LOH & & & & & $.18^{* * *}$ & 0.05 \\
\hline$R^{2}$ & $.10^{* * * *}$ & & $.47^{* * * *}$ & & $.54^{* * *}$ & \\
\hline$F$ & $121.82^{* * * *}$ & & $705.80^{* * * *}$ & & $523.22^{* * * *}$ & \\
\hline$\Delta R^{2}$ & & & $.37^{* * * *}$ & & $.07^{* * * *}$ & \\
\hline$\Delta F$ & & & $2204.32^{* * * *}$ & & $148.62^{* * *}$ & \\
\hline
\end{tabular}


Table 4 Regression results for locus-of-hope subscales predicting anxiety

\begin{tabular}{|c|c|c|c|c|c|c|}
\hline & \multicolumn{2}{|l|}{ Model 1} & \multicolumn{2}{|l|}{ Model 2} & \multicolumn{2}{|l|}{ Model 3} \\
\hline & $\beta$ & SE & $\beta$ & SE & $\beta$ & SE \\
\hline Age & $-.10^{* * *}$ & 0.02 & -.04 & 0.02 & -.03 & 0.02 \\
\hline Sex & $.08^{* * * *}$ & 0.27 & $.07^{* * * *}$ & 0.26 & $.08^{* * * *}$ & 0.26 \\
\hline Marital status & .02 & 0.38 & .03 & 0.36 & .04 & 0.36 \\
\hline State Internal LOH & & & $-.31^{* * * *}$ & 0.05 & $-.28^{* * * *}$ & 0.06 \\
\hline State External-family LOH & & & & & $-.06^{* *}$ & 0.05 \\
\hline State External-peer LOH & & & & & $.05^{*}$ & 0.05 \\
\hline State External-spiritual LOH & & & & & $-.06^{* *}$ & 0.04 \\
\hline$R^{2}$ & $.02^{* * * *}$ & & $.11^{* * * *}$ & & $.11^{* * * *}$ & \\
\hline$F$ & $17.85^{* * * *}$ & & $98.84^{* * * *}$ & & $523.22^{* * * *}$ & \\
\hline$\Delta R^{2}$ & & & $.09^{* * * *}$ & & $.01^{* * * *}$ & \\
\hline$\Delta F$ & & & $2204.32^{* * * *}$ & & $148.62^{* * *}$ & \\
\hline
\end{tabular}

\section{Theoretical Implications}

But what is theoretically interesting is how the temporal state locus-of-hope might reveal very specific workings of hope in the context of the COVID-19 situation. During the time of the survey, Filipinos were required to stay at home under the enhanced community quarantine. Most Filipinos are presumably quarantined with their families, and not directly interacting with their friends and peers. This assumption is somewhat consistent with the result that state external-peer locus-of-hope was related to well-being the weakest compared to the other state locus-of-hope dimension. Now those who report higher levels of state external-peer locus-of-hope are likely to be those who are not at home with their families and are more dependent on the support of their friends and peers during the quarantine. This could mean that they are among those who have been exempted from the quarantine to work in what have been considered essential sectors of the economy or that are staying with friends because they are restricted from travelling to their homes. The specific circumstances of those who report higher state external-peer locus-of-hope might explain the positive relationship with anxiety. We cannot know for sure if our speculation is correct, but what this specific result shows is the usefulness of making a theoretical and empirical distinction between the temporal and disposition aspects of these locus-of-hope dimensions.

In theory, a person's state locus-of-hope should vary within a range anchored on the person's trait or disposition locus-ofhope (Snyder et al. 1996). Very challenging circumstances, like the unexpected difficulties and uncertainties amid the COVID-19 outbreak might lower specific levels of locus-ofhope. Presumably, positive experiences, like getting a promotion at work or experiencing success in a previously unfeasible task might increase specific levels of locus-of-hope, as well.
How and to what extent such circumstances vary one's state locus-of-hope within a range around one's disposition locusof-hope is a matter we cannot address in the current study as the we did not measure dispositional locus-of-hope. So, for example, we cannot determine whether the participants in the study actually experienced decreases in their state externalpeer locus-of-hope relative to their disposition external-peer locus-of-hope. But given that the agency and pathway components of the external locus-of-hope dimensions are related to actors (family members and peers) in the individual's environment who might also be affected by the external social changes (e.g., COVID-outbreak, quarantine), it is possible that this type of locus-of-hope might be more be affected by such changes.

Interestingly, what the results point to is that there might also be a change in the efficacy of the locus-of-hope dimensions in influencing individuals' well-being, which leads to another important theoretical question that could be addressed in future studies. Between dispositional and state locus-ofhope, which would better predict an individual's well-being and coping during uncertain and unusual situations like the COVID-19 outbreak? Would there be differences in the efficacy of each locus-of-hope dimension relative to the disposition and trait measures? What types of external events would moderate the efficacy of one type of state or dispositional locus-of-hope but not the others?

Another interesting theoretical question relates to a limitation of the current study, which used state measures of anxiety and well-being. Anxiety has trait and state measures (Spielberger et al. 1983), and well-being is also recognized as having trait-like stability and state-like alterability (Eid and Diener 2004). Our results attempted to establish criterion validity using state measures, and they do not indicate how state locus-of-hope might predict more trait-like measures of 
well-being and anxiety. Related to the earlier discussion, we could also ask whether how state or dispositional locus-ofhope relate to either state or trait measures of anxiety and well-being.

\section{Future Research}

As the main purpose of this study was to develop and test the validity of the state locus-of-hope scale, many theoretically important questions are not adequately addressed as we noted in the preceding section. In this regard, there are interesting research question that can be addressed in future studies. As noted, questions about the relationship between dispositional and state locus-ofhope and about the predictive validity of dispositional relative to state locus-of-hope dimensions could be addressed by research that includes both types of measures. Longitudinal research designs would help in clarifying how state locus-of-hope dimensions vary with reference to disposition locus-of-hope, and in helping understand how large-scale social change like the COVID-19 outbreak affect locus-of-hope dimensions and their specific associations with state-like and traitlike dimensions of well-being.

Our study only provided initial evidence for the structural validity, convergent and discriminant validity, and criterion validity the state locus-of-hope measure. Future research could go further in establishing stronger evidence for construct validity and also predictive validity of the subscales. As the external locus-of-dimensions were conceptualized to be particularly relevant in collectivistic societies, it is also important that the measure be validated across a wider variety of cultures, including more individualistic cultures.

\section{Conclusion}

Snyder et al. (1996) pointed to dispositional and state measures of hope as having distinct uses depending on the goals of the particular investigation of hope. As our results suggest, during the COVID-19 outbreak in Metro Manila, changes in people's social resources during community quarantine may impact their hope thinking and psychological well-being. Understanding people's state hope help towards understanding psychological mechanisms that could buffer the effects of similar pandemics and similar social crises. More research is necessary before we can fully determine how the dispositional and state versions of locus-of-hope explain different psychological processes and outcomes amid crisis situations similar to what many people are facing during COVID-19 outbreak in 2020 . But the results of the current study point to the validity of a short self-report measure that could be used for future investigations.
Acknowledgements We thank the efforts of the Research Team of LifeRisksPH in building the online platform for the data collection of this research: Adrian Paul Liangco, John Ian Wilzon Dizon, and Leandro Adison David.

Availability of Data and Material/Code Availability All pertinent data, materials, and codes for analysis will be made available by the authors upon written request by any party.

Authors' Contribution Both authors contributed equally to the manuscript and are co-first authors of the work; the names are arranged alphabetically.

\section{Compliance with Ethical Standards}

Conflict of Interest Both authors declare no conflict of interests associated with this research project or the manuscript.

\section{Appendix}

State Locus-of-Hope Scale Filipino sample items (English translation in parentheses).

State internal locus-of-hope

- Agency: Naaabot ko ang mga layuning itinakda ko para sa aking sarili ngayon. (I meet the goals that I set for myself now)

- Pathway: Masigasig akong gumagawa ng paraan para maabot ang aking mga mithiin ngayon. (I energetically find way to pursue my important goals right now.)

State external-family locus-of-hope

- Agency: Kumpiyansa ako na susuportahan ako ng aking pamilya sa mga importanteng layunin ko ngayon. (I am confident that my family will support me in the goals that are important to me now)

- Pathway: Tinulungan ako ng aking pamilya ngayon na humanap ng mga paraan upang maabot ang mga inaasam ko ngayon. (My family presently helps me find ways to solve my current problems.)

State external-peer locus-of-hope

- Agency: Naabot ko ang aking mga layunin sa buhay ngayon dahil sa tulong ng aking mga kaibigan. (I am able to attain my current goals in life with the help of my friends)

- Pathway: Nakakaisip ang mga kaibigan ko ng paraan para lutasin ang mga problem ko ngayon. (My friends often find lots of ways to help me solve my current problems.)

State external-spiritual locus-of-hope 
- Agency: Maaabot ko ang mga layunin ko sa buhay ngayon kung magtitiwala ako sa Diyos. (I will attain my current life goals by trusting God)

- Pathway: Maraming paraan ang Diyos upang maabot ko ang aking mga mithiin ngayon. (God has many different ways of letting me attain my goals now.)

\section{References}

Adelabu, D. H. (2008). Future time perspective, hope, and ethnic identity among African American adolescents. Urban Education, 43(3), 347-360. https://doi.org/10.1177/0042085907311806.

Arnau, R., Rosen, D., Finch, J., Rhudy, J., \& Fortunato, V. (2007). Longitudinal effects of hope on depression and anxiety: A latent variable analysis. Journal of Personality, 75(1), 43-63. https://doi. org/10.1111/j.1467-6494.2006.00432.x.

Berendes, D., Keefe, F. J., Somers, T. J., Kothadia, S. M., Porter, L. S., \& Cheaveans, J. S. (2010). Hope in the context of lung cancer: Relationship of hope to symptoms and psychological distress. Journal of Pain and Symptom Management, 40(2), 174-182. https://doi.org/10.1016/j.jpainsymman.2010.01.014.

Bernardo, A. B. I. (2010). Extending hope theory: Internal and external locus of trait hope. Personality and Individual Differences, 49, 944 949. https://doi.org/10.1016/j.paid.2010.07.036.

Bernardo, A. B. I. (2015). Hope in early adolescence: Measuring internal and external locus-of-hope. Child Indicators Research, 8, 699-715. https://doi.org/10.1007/s12187-014-9254-6.

Bernardo, A. B. I., \& Estrellado, A. F. (2014). Measuring hope in the Philippines: Validating the short version of the locus-of-Hope scale in Filipino. Social Indicators Research, 119, 1649-1661. https://doi. org/10.1007/s11205-013-0573-7.

Bernardo, A. B. I., \& Estrellado, A. F. (2017a). Locus-of-hope and helpseeking intentions of Filipino battered women victims of intimate partner violence. Current Psychology, 36, 66-75. https://doi.org/10. 1007/s12144-015-9385-z.

Bernardo, A. B. I., \& Estrellado, A. F. (2017b). Subjective well-being of Filipino women who experienced intimate partner violence: A person-centered analysis. International Journal for the Advancement of Counselling, 39, 360-376. https://doi.org/10. 1007/s10447-017-9303-1.

Bernardo, A. B. I., Khan, A., \& Salanga, M. G. C. (2018a). Hope and satisfaction with life: Testing the mediating roles of self-esteem in three Asian cultures. Acción Psicológica, 15(2), 69-82. https://doi. org/10.5944/ap.15.2.23456.

Bernardo, A. B. I., \& Resurreccion, K. F. (2018). Financial stress and well-being of Filipino students: The moderating role of external locus-of-hope. Philippine Journal of Psychology, 51(1), 33-61. https://doi.org/10.31710/pjp/0051.01.03.

Bernardo, A. B. I., Salanga, M. G. C., Khan, A., \& Yeung, S. S. (2016). Internal and external loci-of-hope predict use of individual and collaborative learning strategies: Evidence from university learners in four Asian cities. The Asia-Pacific Education Researcher, 25, $367-$ 376. https://doi.org/10.1007/s40299-015-0249-y.

Bernardo, A. B. I., Wang, T. Y., Pesigan, I. J. A., \& Yeung, S. S. (2017). Pathways from collectivist coping to life satisfaction among Chinese: The roles of locus-of-hope. Personality and Individual Differences, 106, 253-256. https://doi.org/10.1016/j.paid.2016.10. 059

Bernardo, A. B. I., Yeung, S. S., Resurreccion, K. F., Resurreccion, R. R., \& Khan, A. (2018b). External locus-of-hope, well-being, and coping of students: A cross-cultural investigation within Asia. Psychology in the Schools, 55, 908-923. https://doi.org/10.1002/pits.22155.

Bryce, C. I., Alexander, B. L., Fraser, A. M., \& Fabes, R. A. (2020). Dimensions of hope in adolescence: Relations to academic functioning and well-being. Psychology in the Schools, 57(2), 171-190. https://doi.org/10.1002/pits.22311.

Cheavens, J.S., Michael, S.T., \& Snyder, C.R. (2005). The correlates of hope: Psychological and physiological benefits. In J.A. Eliott (Ed.), Interdisciplinary perspectives on hope (p. 119-132). Nova Science.

Curry, L. A., Snyder, C. R., Cook, D. L., Ruby, B. C., \& Rehm, M. (1997). Role of hope in academic and sport achievement. Journal of Personality and Social Psychology, 73(6), 1257-1267. https:// doi.org/10.1037/0022-3514.73.6.1257.

Datu, J. A. D., \& Mateo, N. J. (2017). How to combat the negative impact of discrimination in a collectivist context? The safeguarding function of peer-oriented hope. Psychology, Health \& Medicine, 22, 345-351. https://doi.org/10.1080/13548506.2016.1164875.

Dixson, D. D. (2019). Hope into action: How clusters of hope relate to success-oriented behavior in school. Psychology in the Schools, 56(9), 1493-1511. https://doi.org/10.1002/pits.22299.

Du, H., Bernardo, A. B. I., \& Yeung, S. S. (2015). Locus-of-hope and life satisfaction: The mediating roles of personal self-esteem and relational self-esteem. Personality and Individual Differences, 83, 228233. https://doi.org/10.1016/j.paid.2015.04.026.

Du, H., \& King, R. B. (2013). Placing hope in self and others: Exploring the relationships among self-construals, locus of hope, and adjustment. Personality and Individual Differences, 54, 332-337. https:// doi.org/10.1016/j.paid.2012.09.015.

Eid, M., \& Diener, E. (2004). Global judgments of subjective well-being: Situational variability and long-term stability. Social Indicators Research, 65(3), 245-277. https://doi.org/10.1023/B:SOCI. 0000003801.89195.bc.

Epstein, J., Santo, R. M., \& Guillemin, F. (2015). A review of guidelines for cross-cultural adaptation of questionnaires could not bring out a consensus. Journal of Clinical Epidemiology, 68(4), 435-441. https://doi.org/10.1016/j.jclinepi.2014.11.021.

Fukui, S., Starnino, V. R., Susana, M., Davidson, L. J., Cook, K., Rapp, C. A., \& Gowdy, E. A. (2011). Effect of wellness recovery action plan (WRAP) participation on psychiatric symptoms, sense of hope, and recovery. Psychiatric Rehabilitation Journal, 34(3), 214-222. https://doi.org/10.2975/34.3.2011.214.222.

Galiana, L., Oliver, A., Sancho, P., \& Tomás, J. M. (2015). Dimensionality and validation of the dispositional Hope scale in a Spanish sample. Social Indicators Research, 120(1), 297-308. https://doi.org/10.1007/s11205-014-0582-1.

Gana, K., Daigre, S., \& Ledrich, J. (2013). Psychometric properties of the French version of the adult dispositional hope scale. Assessment, 20(1), 114-118. https://doi.org/10.1177/1073191112468315.

Hair, J., Black, W., Babin, B., \& Anderson, R. (2010). Multivariate data analysis (7th ed.). Prentice-Hall.

Hu, L. T., \& Bentler, P. M. (1999). Cutoff criteria for fit indexes in covariance structure analysis: Conventional criteria versus new alternatives. Structural Equation Modeling, 6(1), 1-55. https://doi. org/10.1080/10705519909540118.

Jiang, Y., Ren, Y., Liang, Q., \& You, J. (2018). The moderating role of trait hope in the association between adolescent depressive symptoms and nonsuicidal self-injury. Personality and Individual Differences, 135, 137-142. https://doi.org/10.1016/j.paid.2018.07.010.

Jiang, Y., Ren, Y., Zhu, J., \& You, J. (2020). Gratitude and hope relate to adolescent nonsuicidal self-injury: Mediation through selfcompassion and family and school experiences. Current Psychology. Advanced online publication. https://doi.org/10.1007/ s12144-020-00624-4.

Jin, B., \& Kim, Y. C. (2019). Rainbows in the society: A measure of hope for society. Asian Journal of Social Psychology, 22(1), 18-27. https://doi.org/10.1111/ajsp.12339. 
Juntunen, C. L., \& Wettersten, K. B. (2006). Work hope: Development and initial validation of a measure. Journal of Counseling Psychology, 53(1), 94-106. https://doi.org/10.1037/0022-0167.53. 1.94.

Keyes, C. L. M. (2002). The Mental Health Continuum: From languishing to flourishing in life. Journal of Health and Social Behavior, 43(2), 207-222

Lucas, R. I. G., \& Ouano, J. A. (2018). Hope and academic achievement among young Filipino college indigent students. Asia-Pacific Social Science Review, 17, 160-165.

Malhotra N.K., \& Dash S. (2011). Marketing research an applied orientation. Pearson.

Markus H.R, \& Kitayama S. (2003). Models of agency: Sociocultural diversity in the construction of action. In V. Murphy-Berman, \& J. J. Berman (eds.), Cross- cultural differences in perspectives on the self (pp. 1-57). University of Nebraska Press.

Moreira, C. R., Nascimento-Junior, J. R. A., Codonhato, R., \& Fiorese, L. (2018). Psychometric properties of dispositional hope scale for Brazilian sport context. The Spanish Journal of Psychology, 21, E15. https://doi.org/10.1017/sjp.2018.18.

Munoz, R. T., Quinton, K. A., Worley, J. A., \& Hellman, C. M. (2019). Locus of hope: External hope in parents/guardians as an antecedent of adolescents' internal hope and life satisfaction. Child Indicators Research, 12(3), 1107-1124. https://doi.org/10.1007/s12187-0189566-z.

Raats, C., Adams, S., Savahl, S., Isaacs, S., \& Tiliouine, H. (2019). The relationship between hope and life satisfaction among children in low and middle socio-economic status communities in Cape Town, South Africa. Child Indicators Research, 12(2), 733-746. https:// doi.org/10.1007/s12187-018-9549-0.

StataCorp. (2015). Stata statistical software: Release 14. StataCorp.

Snyder, C.R. (1994). The psychology of hope. Free Press

Snyder, C. R., Harris, C., Anderson, J. R., Holleran, S. A., Irving, L. M., Sigmon, S. T., Yoshinobu, L., Gibb, J., Langelle, C., \& Harney, P. (1991). The will and the ways: Development and validation of an individual-differences measure of hope. Journal of Personality and Social Psychology, 60, 570-585. https://doi.org/10.1037//00223514.60.4.570.

Snyder, C. R., Sympson, S. C., Ybasco, F. C., Border, T. F., Babyak, M. A., \& Higgins, R. L. (1996). Development and validation of the state Hope scale. Journal of Personality and Social Psychology, 70, 321335. https://doi.org/10.1037/0022-3514.70.2.321.

Spielberger, C., Gorsuch, R., Lushene, R., Vagg, P., \& Jacobs, G. (1983). Manual for the state-trait anxiety inventory. Consulting Psychologists Press.
Spitzer, R. L., Kroenke, K., Williams, J. B., \& Löwe, B. (2006). A brief measure for assessing generalized anxiety disorder: the GAD-7. Archives of Internal Medicine, 166(10), 1092-1097. https://doi. org/10.1001/archinte.166.10.1092.

Sun, Q., Ng, K. M., \& Wang, C. (2012). A validation study on a new Chinese version of the dispositional Hope scale. Measurement and Evaluation in Counseling and Development, 45(2), 133-148. https://doi.org/10.1177/0748175611429011.

Tanaka, J. S. (1987). "how big is big enough?": Sample size and goodness of fit in structural equation models with latent variables. Child Development, 58, 134-146. https://doi.org/10.2307/1130296.

Tomás, J. M., Gutiérrez, M., Georgieva, S., \& Hernández, M. (2020). The effects of self-efficacy, hope, and engagement on the academic achievement of secondary education in the Dominican Republic. Psychology in the Schools, 57(2), 191-203. https://doi.org/10. 1002/pits.22321.

Vernberg, D., Snyder, C. R., \& Schuh, M. (2005). Preliminary validation of a hope scale for a rare health condition using web-based methodology. Cognition \& Emotion, 19(4), 601-610. https://doi.org/10. 1080/02699930441000256.

Vilaythong, A. P., Arnau, R. C., Rosen, D. H., \& Mascaro, N. (2003). Humor and hope: Can humor increase hope? Humor, 16(1), 79-90. https://doi.org/10.1515/humr.2003.006.

Visser, P. L., Loess, P., Jeglic, E. L., \& Hirsch, J. K. (2013). Hope as moderator of negative life events and depressive symptoms in a diverse sample. Stress and Health, 29, 82-88. https://doi.org/10. 1002/smi.2433.

Wagshul, Y. D. (2019). Effect of external locus-of-hope on acquired capability for suicide. Suicide and Life-threatening Behavior, 49(6), 1541-1551. https://doi.org/10.1111/sltb.12539.

You, S., Furlong, M. J., Felix, E., Sharkey, J. D., Tanigawa, D., \& Green, J. G. (2008). Relations among school connectedness, hope, life satisfaction, and bully victimization. Psychology in the Schools, 45(5), 446-460. https://doi.org/10.1002/pits.20308.

Zhou, X., Zhen, R., \& Wu, X. (2019). Understanding the relation between gratitude and life satisfaction among adolescents in a post-disaster context: Mediating roles of social support, self-esteem, and hope. Child Indicators Research, 12(5), 1781-1795. https://doi.org/10. 1007/s12187-018-9610-z.

Publisher's Note Springer Nature remains neutral with regard to jurisdictional claims in published maps and institutional affiliations. 